\title{
Two-dimensional stimulus control in the goldfish (Carassius auratus)
}

\author{
Satoko Ohinata \\ Japan Women's University
}

The effects of dimensional control to compound stimuli have been investigated from many viewpoints in the pigeon. In the goldfish, however, little is known directly about some control of responding by dimension that comprise a compound stimulus.

The present. study was concerned with the characteristics of the two-dimensional control in the goldfish. The study employed wavelength as one stimulus dimension and a visual-spatial dimension, angular orientation of a band of light, as the second dimension. After the single-stimulus training with a compound stimulus, the subjects were tested for generalization along two dimensions.

\section{Method}

Subjects: The subjects were twelve 15-18 cm. common goldfish (Carassius auratus) obtained from a local supplier, all experimentally naive but throughly adapted to life in the laboratory. They were maintained on approximately $23 \mathrm{hr}$. of food deprivation; rewards earned in the experimental sessions were supplemented by postsession feedings. No subject was discarded as untrainable or ill. Complete data were obtained on $12 \mathrm{Ss}$, six in each of two groups.

Apparatus: The apparatus was an aquatic version of the standard one-key Skinner box, designed for key-striking. A detailed description of the apparatus appears eleswhere (OHINATA, 1). The special feature of the present apparatus, however, was that only a narrow band of colored light was transmitted to the key, and this band of light could be rotated about its center to provide various degrees of angular orientation. Excepting the portion of the band, the circular translucent key was masked by means of an opaque frame so that the band running through its 
center, $4 \mathrm{~cm}$. in length and $0.5 \mathrm{~cm}$. in width, was exposed to the light beam.

Five Kodak Wratten filters, Nos. 65, 74, 99, 73, and 72B, yeilding transmitted peak wavelengths of 501,538,555,576, and $606 \mathrm{~nm}$., respectively, were used in order to produce the chromatic stimuli. The filters were mounted one at a time in a holder in the light path from an Olympus microscope illuminator with a lamp of $6 \mathrm{~V}-5 \mathrm{~A}$ (approximately Illuminant A). The illuminance of each chromatic stimulus on the key was equated with neutral density filters and neutral density wedges, but no attempt was made to equate the spectrum lights in terms of the goldfish visibility function (YAGER, 2).

Procedure: Following magazine training, all Ss were trained to key strike according to a set schedule covering five days. The schedule was consisted of one day of continuous reinforcements, two days of FR- 2 training and two more days of FR- 4 training. Each $\mathrm{S}$ had ten reinforced trials each day. During the stage of continuous reinforcements, an overhead light was on in the apparatus, but in subsequent stages the only illumination in the chamber was provided by the light from the key. In training sessions for Group 1, the narrow band on the key was illuminated by light of $555 \mathrm{~nm}$. and was in a vertical position $\left(90^{\circ}\right)$, and for Group 2 by $555 \mathrm{~nm}$. at an angle of $135^{\circ}$ degrees (rotated $45^{\circ}$ to the right of $90^{\circ}$ ).

On the day following the end of key-strike training, training proper was begun on a fixed-interval (FI) schedule, and all Ss received ten day training. Twenty 20 -sec. stimulus-on periods, alternating with 10 -sec. interval stimulus-off periods in darkness, were given each day. The first response after the 20-sec. lock-up on stimulus-on trials produced a reinforcement - the key light was turned off and a reinforcement period intervened - after which the feeder light was turned off, causing a $1^{-}$sec. stimulus-off period. During stimulus-off periods, a shutter was operated so as to remove the light from the key and to leave the experimental chamber dark. A live-worm dispenser mounted on the top of the apparatus delivered reinforcements, but reinforcements were never given during stimulus-off periods. Only during the reinforcement period, the feeding area was illuminated by a white light produced through a color-temperature conversion filter (HOYA B65, $\left.2848^{\circ} \mathrm{K} \rightarrow 6500^{\circ} \mathrm{K}\right)$.

On day 11 all Ss were tested for stimulus generalization. Immediately before testing Ss were reinforced for striking in the presence of training stimulus on two 
20-sec. fixed interval trials. Subsequent generalization testing was carried out in extinction. Subjects in Group 1 were presented with all possible combinations of five values of wavelength, $501,538,555,576$, and $606 \mathrm{~nm}$., and five values of angular orientation, $30^{\circ}, 60^{\circ}, 90^{\circ}, 120^{\circ}$, and $150^{\circ}$. Subjects in Group 2 were presented with all possible combinations of five values of wavelength, 501, 538, 555, 576, and 606 $\mathrm{nm}$., and five values of angular orientation, $75^{\circ}, 105^{\circ}, 135^{\circ}, 165^{\circ}$, and $195^{\circ}$. Each of these 25 stimulus combinations was presented four times, and within each of the four blocks, stimulus combinations were arranged in a different random order. Each stimulus presentation lasted for $30 \mathrm{sec}$. and was followed by a 10-sec. dark period, during which stimuli were changed. On the following day all Ss received a second generalization test, administered in the same manner as on the first day of testing. The entire experimental sequence was scheduled and recorded by the Mult $\cdot$ FI $\cdot$ Ext $\cdot$ Random-Logic Equipment ${ }^{1)}$.

\section{Results and Discussion.}

Data from the first and second tests for each $\mathrm{S}$ were combined because the two tests constituted serial phases of extinction without being intervened by training. In order that each number of responses to stimuli presented in the generalization test may go between 0.00 and 6.00 , the maximum number of responses of each $\mathrm{S}$ was transformed into the new index, 6.00 , respectively. Thus, mean total responses are plotted in the figures on the same standard as a function of wavelength, with angular orientation as the parameter, and as a function of angular orientation, with wavelength as the parameter. Fig. 1 gives the results from Ss in Group 1, and Fig. 2 from Ss in Group 2.

The generalization gradients for Group 1 and 2 were similar in slope and symmetry about the vertical. Most responses in testing occurred to the values of training stimulus, $555 \mathrm{~nm}$. and $90^{\circ}$ for Group 1 , and $555 \mathrm{~nm}$. and $135^{\circ}$ for Group 2 . Inspection of the figures reveals that there was some control of responding by each dimension.

1) The author is indebted to Takayuki Sakagami at Department of Psychology, Keio

University, who made the Mult $\cdot$ FI $\cdot$ Ext $\cdot$ Random-Logic Equipment available. 

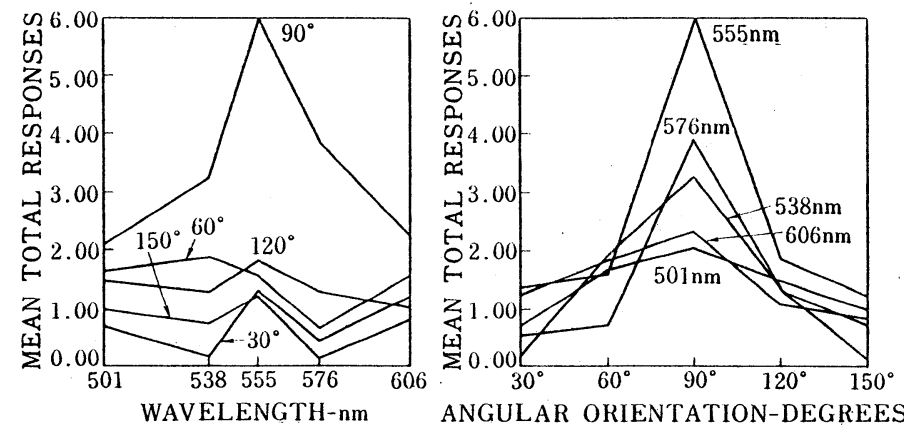

Fig. 1 Mean total responses to wavelength and angular orientation stimuli on the generalization test (Group 1).
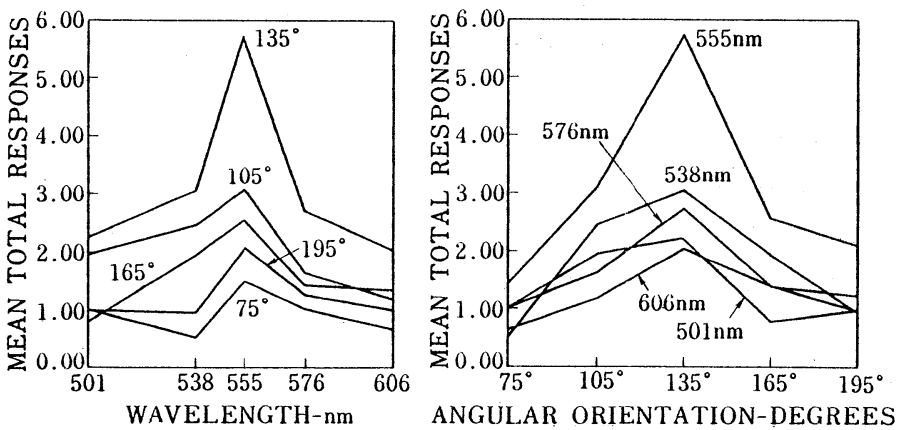

Fig. 2 Mean total responses to wavelength and angular orientation stimuli on the generalization test (Group 2).

The experiments of this article show that a color can not be separated from an angular orientation stimulus. An angular orientation always has a color, and subjects are shown to attend to the color-angular orientation relationship. Future studies using other dimensions and methods of testing may provide more information about the manner in which multidimensional generalization occurs. 


\section{REFERENCES}

1. Ohinata, S. Postdiscrimination shift of the goldfish (CARASSIUS AURATUS) on a visual wavelength continuum. The Annual of Animal Psychology, 1978, 28, 113-122.

2. YAGER, D. Behavioral measures and theoretical analysis of spectral sensitivity and spectral saturation in the goldfish, Carassius auratus. Vision Research, 1967, 7, 707-727.

（最終受付１985年10月15日） 